\title{
Cortically Supported Custom-Made Subperostealis Implant - A Case Report
}

\author{
János Kónya* and Klaudia Kulcsár \\ Dent Art Technik Kft, Györ, Hungary \\ *Corresponding author: János Kónya, Dent-Art-Technik Kft, Győr, Hungary
}

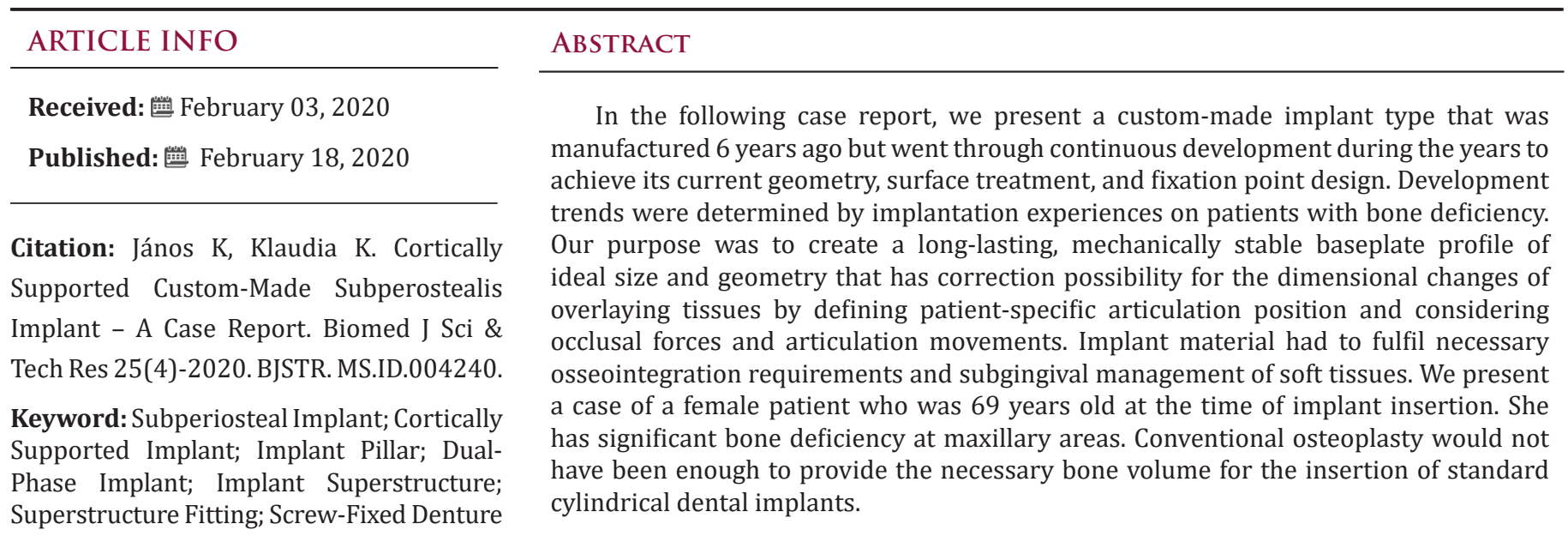

\section{Introduction}

Dental implants are used to replace missing teeth. Implants have different types based on their operating principles and insertion methods. We report a case with a subperiosteal implant, which belongs to the family of custom-made implants as it is impossible to entirely standardize these implants and it is also very difficult to just partly conventionalize them. From a historical point of view, first subperiosteal implants appeared at the end of the 1930s. Dahl was the first to publish a study about them in the beginning of the $1940 \mathrm{~s}$ [1]. This implantation method provides a fixed denture solution for edentulous patients. Early surgical technique consisted of two operations. During the first surgery, gum tissue was opened, and an impression was made to model existing bone anatomy. Implant baseplate insertion required another surgical procedure. This often resulted in posttraumatic effects and complications. Nickel-cobaltchrome metallic alloy was used as implant material, and dentures were fixed to posts protruding from the gum tissue. Although, Dahl's implantation method had several disadvantages: the baseplate was not fixed to mandibular and maxillary bone regions, its fixation was provided only by being embedded in connective tissue. Bacterial and destructive inflammatory processes often occurred due to the surgical procedure, implant material, lack of surface treatment, and lack of design experience with fixation pillars of the implant $[2,3]$. They resulted in high risk of complications, which lead to destructive resorption and relatively high number of inserted implants had to be removed. As a result of this, the implantation procedure had a bad reputation.

However, we completely revised subperiosteal implants thanks to the availability of medical grade titanium, CBCT imaging possibility to substitute physical impressions, and use of virtual design and analysis software. It became possible for us to create permanent functional bone replacements to restore chewing ability of patients with insufficient bone volume for the insertion of cylindrical dental implants. Nowadays, different types of innovation and technological development made it possible to positively change public assessment as well [4-6].

\section{Case Report}

CBCT images of the patient were processed virtually by generating an STL file. The STL file contained data of the precise bone surface based on adjusted parameters. It is a general problem that thin details of cortical bone ridge do not provide sufficient $x$-ray shadow which can lead to deficiencies on the bone surface [7-9]. 
These holes can be filled by the software if they are not excessively large. Every virtual correction that modifies relative position of real existing bone surfaces shall be highlighted on the virtual model to avoid fitting problems later. Figure 1 shows the highlighted area of the corrected surfaces at the extension of the baseplate and the corrected model. The corrected surface generated this way was ready for further design steps. Design started with the virtual replacement of missing teeth based on the relation of articulation and antagonistic teeth. Here in this design step, previous denture of the patient was studied as well to precisely adjust trans-occlusal space, tooth sizes, and later periodontal relations. During the expansion of the baseplate, anatomic details of the bone surface were considered to calculate and minimize necessary expansion dimensions using a simulation software [6]. Boundaries of the expanded baseplate were perforated to increase mechanical stability and provide space for fixation points. When designing these fixation points, thickness of the underlying cortical plate was taken into consideration. Figure 2 shows the virtual image of the denture and its supporting subperiosteal plate.
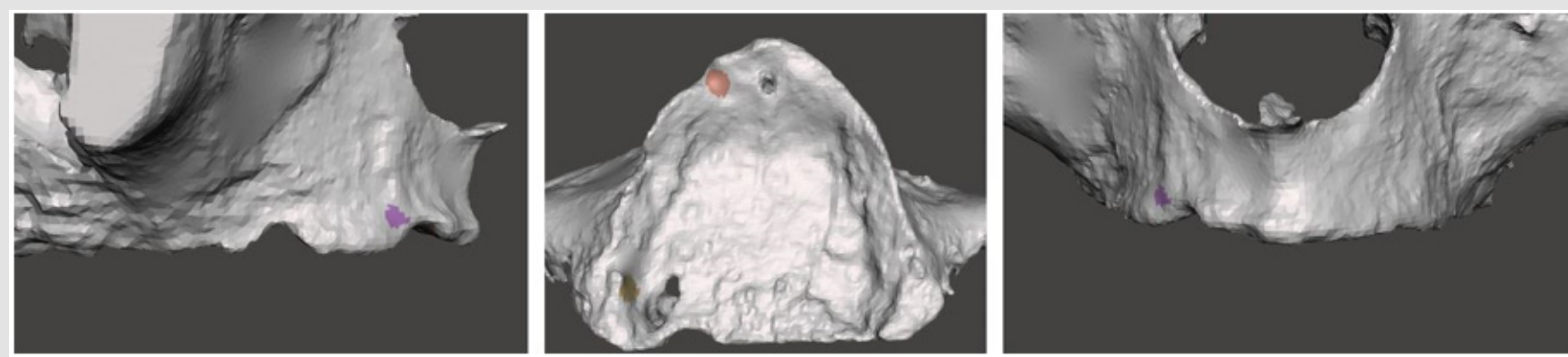

Figure 1: Corrected model of initial condition.
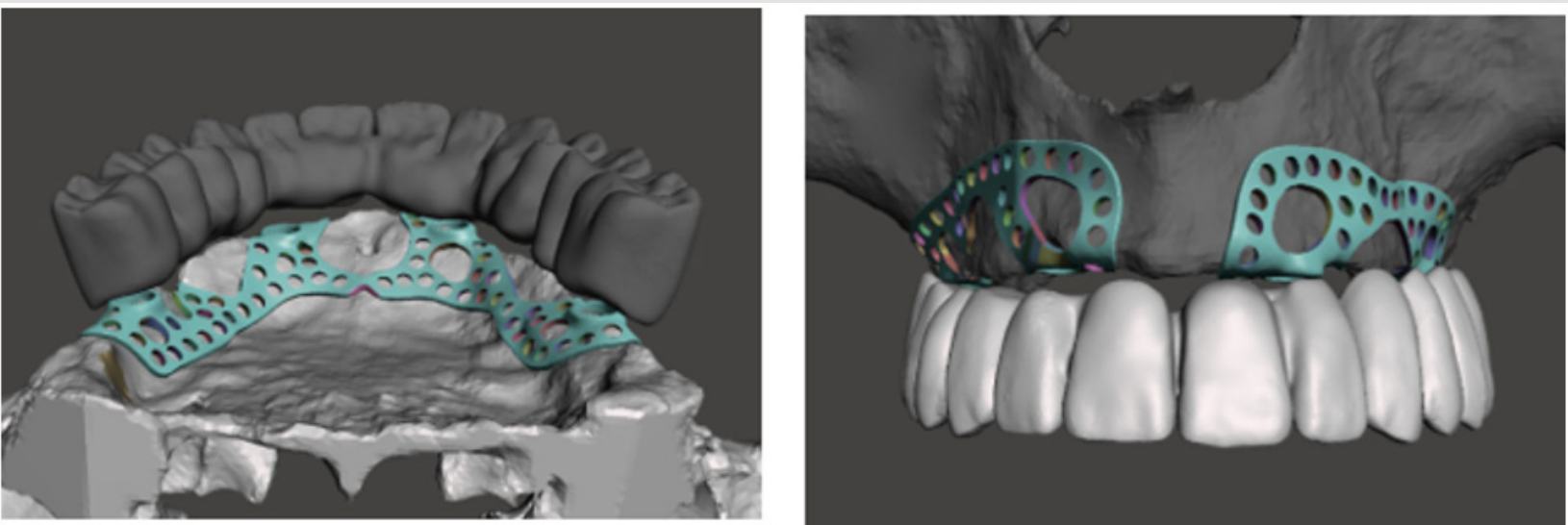

Figure 2: Different views of the designed baseplate and denture.
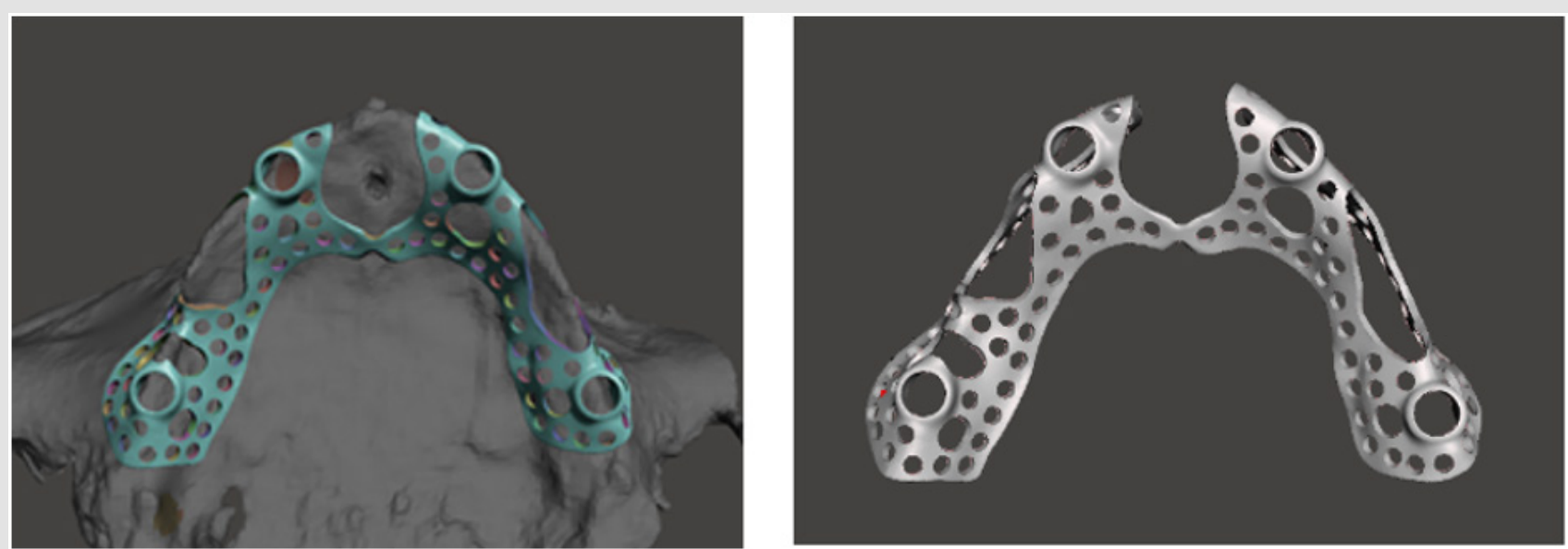

Figure 3: Planned locations of fixation points on the baseplate. 
These pieces of information are necessary for the design of threaded denture fixation points in the trans-occlusal direction. In this phase, a positioning ring was created on the plate that facilitated pillar insertion. Its role was to achieve correct positioning and insertion of the threaded sleeve after printing. The virtually designed plate structure was inspected and approved by the oral surgeon. Figure 3 shows the virtually designed baseplate with its fixation points, which was sent for examination. In the previous steps, a dual threaded multi-body pillar structure had been fixed in the positioning rings of the baseplate. Component no. 1 was the threaded sleeve, which fitted to the baseplate and was later fixed with laser welding. Component no. 2 was the abutment, which was adjustable to different gum tissue levels. It could be replaced to compensate 1 to 3-mm-thick gum tissue levels depending on the change of gum thickness during the healing period after surgery. Component no. 3 was the interface, which was bonded into the denture, while the denture could have been fixed with threaded detachable joint. Component no. 4 was a micro screw that provided denture fixation. All structural components were machined with CNC technology and made from Grade 5 titanium material [10]. Figure 4 presents the structural design of the threaded fixation unit.

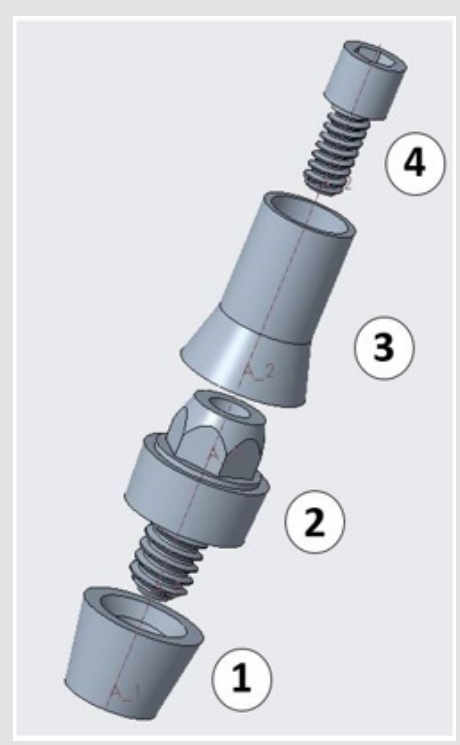

Figure 4: Structural components of the threaded fixation unit.

Subperiosteal framework was physically implemented from Grade 23 Ti-6Al-4V material with LMF additive manufacturing technology using a Sisma MySint 100-type 3D-printer. Figure 5 presents the raw 3D-printed titanium implant baseplate after heat treatment. Assembly of the ready baseplate and pillar structure was carried out by welding the threaded sleeve into its previously defined correct position [11]. Afterwards, surface treatment of the weld joint and the framework was conducted with sand-blasting the entire structure and polishing pillar neck areas in a $1.5-\mathrm{mm}$ - wide line. The last step was acid etching of the plate surface to promote osseointegration. Figure 6 shows component assembly with gum level correction possibility by changing the abutments. Abutments could be changed after implantation as well to readjust red white aesthetics depending on the extent of gum volume change and to sustain cleanability. The custom-made assembled implant structure went through packaging process after ultrasonic cleaning. Its final sterilization took place at the dental clinic before surgical implantation. Figure 7 shows the implant ready for insertion.

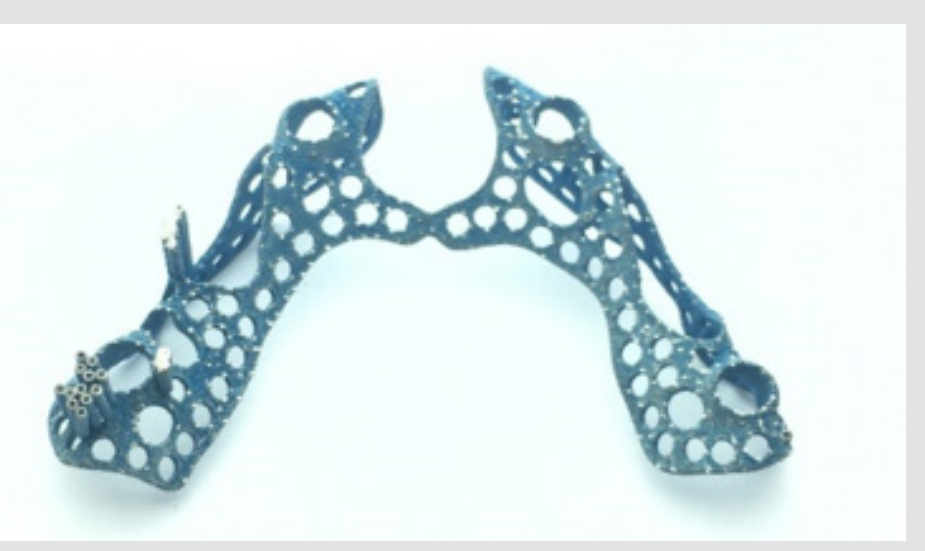

Figure 5: Baseplate of the 3D-printed raw subperiosteal implant. 


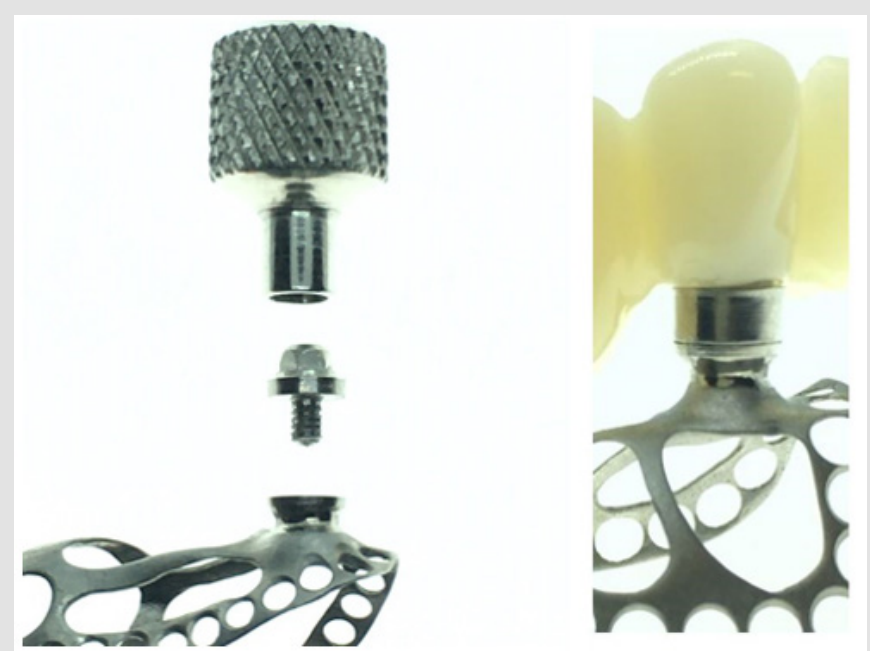

Figure 6: Assembled pieces with gingival correction abutments.

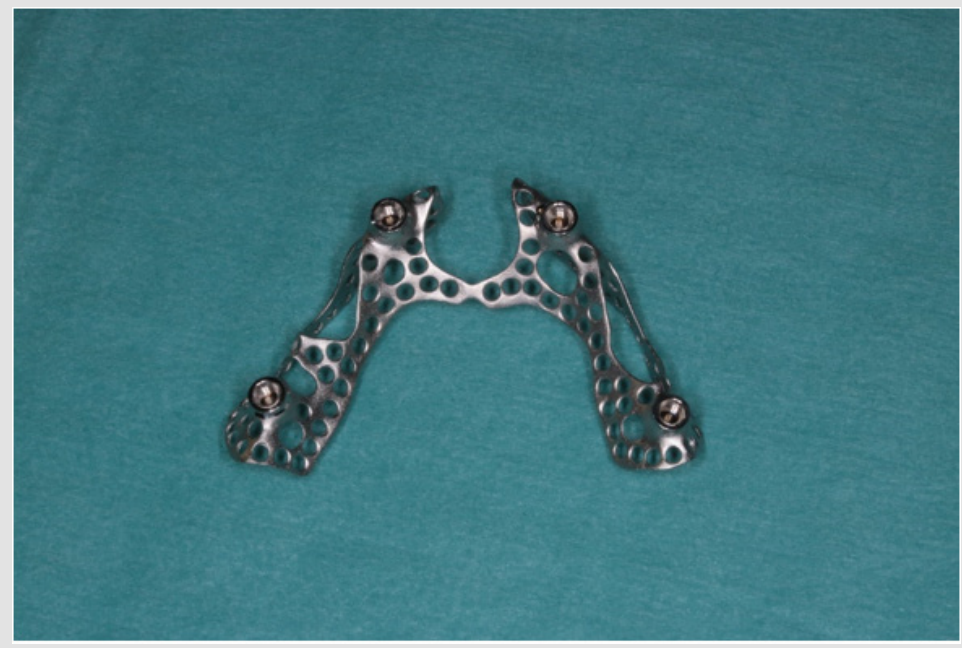

Figure 7: Implant ready for insertion.
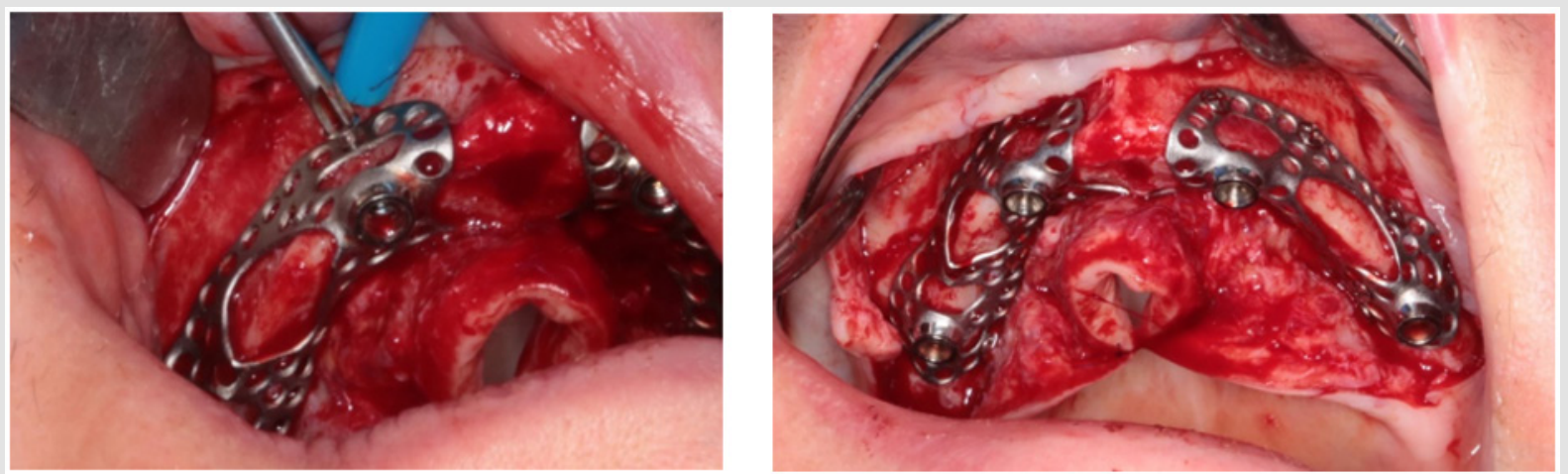

Figure 8: Fitting and fixing the implant on cortical bone

Because titanium baseplate was relatively brittle and could not have been bent, imprecisions of the fine fitting surfaces and deviation caused by STL correction after CBCT imaging were both corrected by burring bone surfaces. In our case, the plate was fixed with 8 pieces of self-tapping cortical screws with the diameter of 1.2 $\mathrm{mm}$. Screws were fitting into the plane defined by perforated screw head grooves. Screw fixation provided primary stability, which is very important considering the immediate loading of the implant. Figure 8 shows fitting and fixation of the implant on cortical bone. The plate was covered with crosslinked collagen membrane at the pillars protruding from epithelial tissue. The rest of the plate was wrapped with PRF membrane to create isolated circumstances for 
osseointegration of the titanium baseplate situated between the perforated bone surface and the membrane. Figure 9 shows the construction of this dual membrane envelope. It was important during suturing of the implant to have tight gum tissue around the epithelial protrusion points. It was vital to achieve long-term implant survival. If this prerequisite is not met, another surgery will be necessary just to create tight gum tissue. Before this, plate insertion is not possible at all. Figure 10 shows tight gum tissue fitting around protrusion points of the pillars and closed but stressfree sutures.

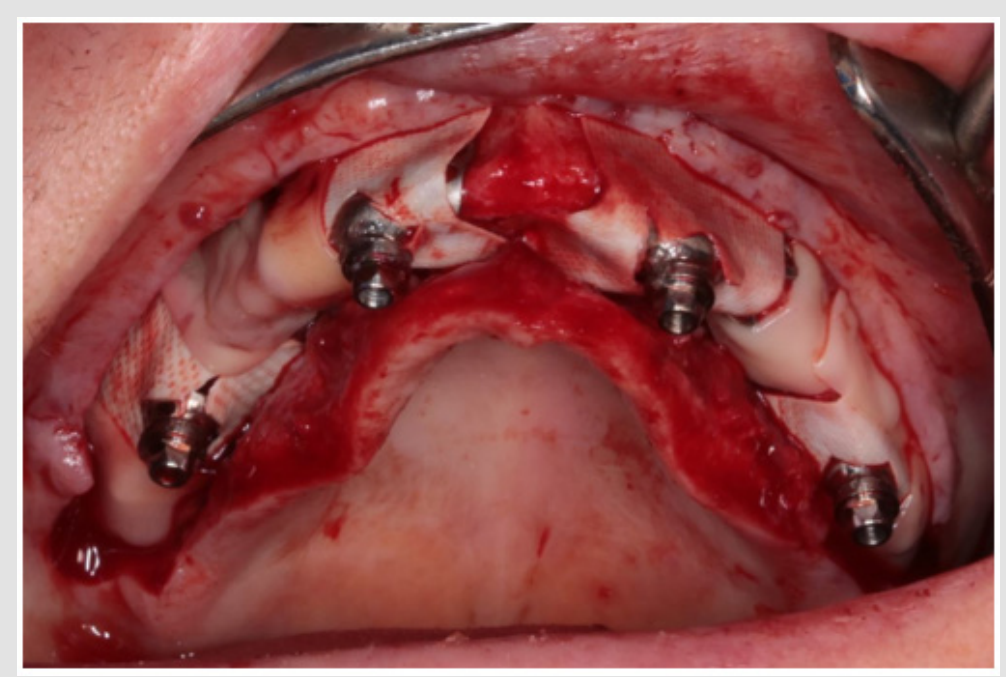

Figure 9: Fitting and fixing the implant on cortical bone

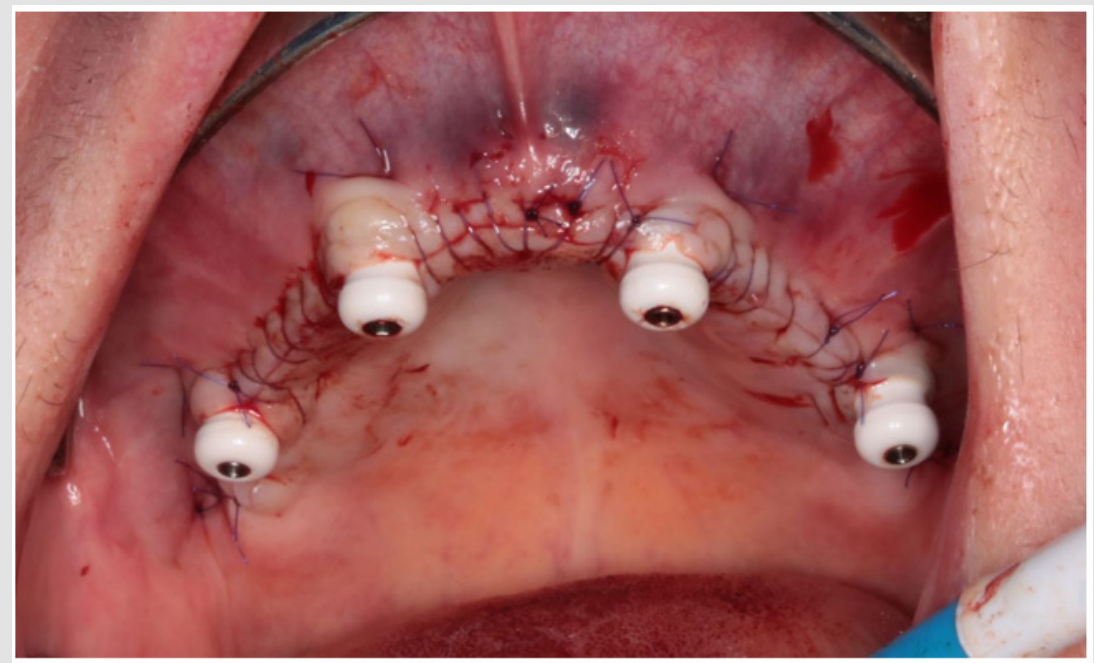

Figure 10: Closing epithelial tissues.

An improperly fixed removable denture could have caused great damage in the inserted plate. Thus, an immediate load fixed temporary denture was created. Cleanability of the temporary denture is an important factor to achieve irritation-free healing. It is also very important to precisely adjust temporary denture articulation in order to achieve well-balanced baseplate loading. Figure 11 shows the immediate load temporary denture fitted to the inserted implant structure. During suture removal, temporary bridge replacement was corrected according to epithelial impression. It is shown in Figure 12 At 3-weeks follow up, control CBCT images were made after examining cleanability of the temporary denture. CBCT images can be seen in Figure 13 Images provide a good demonstration of the fitting, fixing screw positions, and nesting of the implant baseplate to the neighbouring tissues. Figure 14 shows the healed state and the use of abutments that precisely fitted gum tissue levels. 


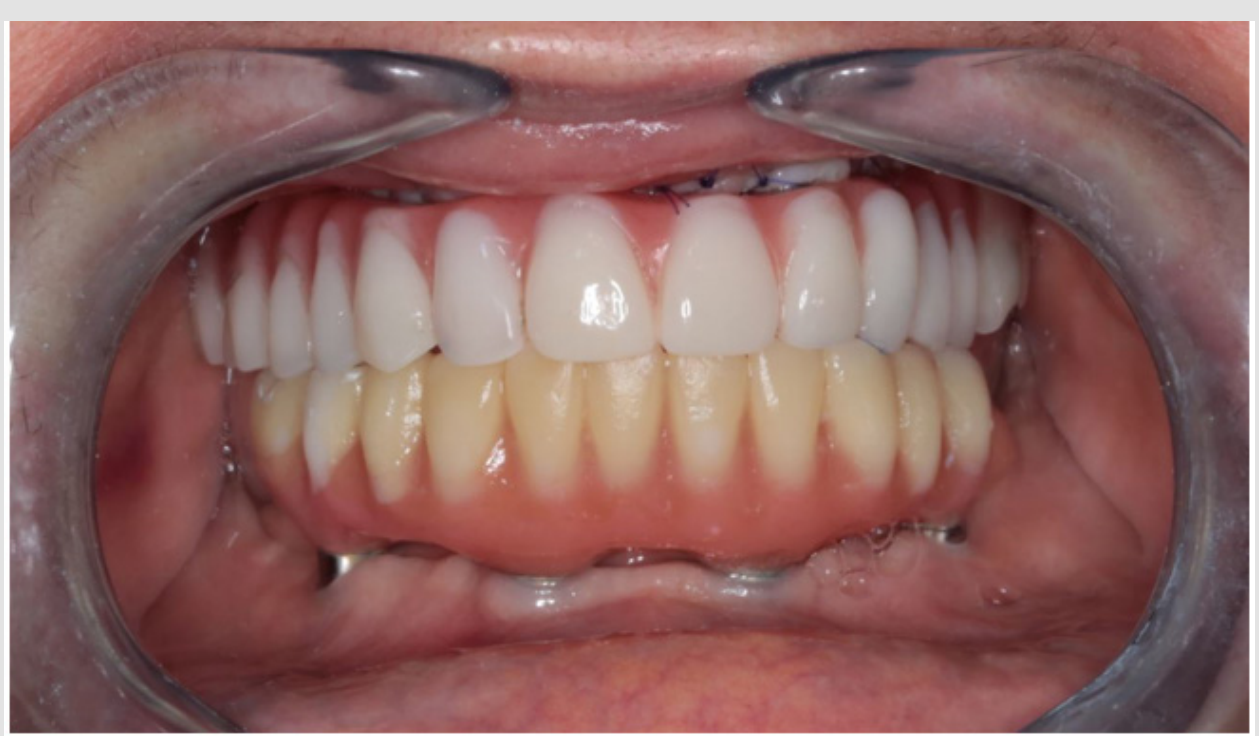

Figure 11: Immediate load temporary denture.

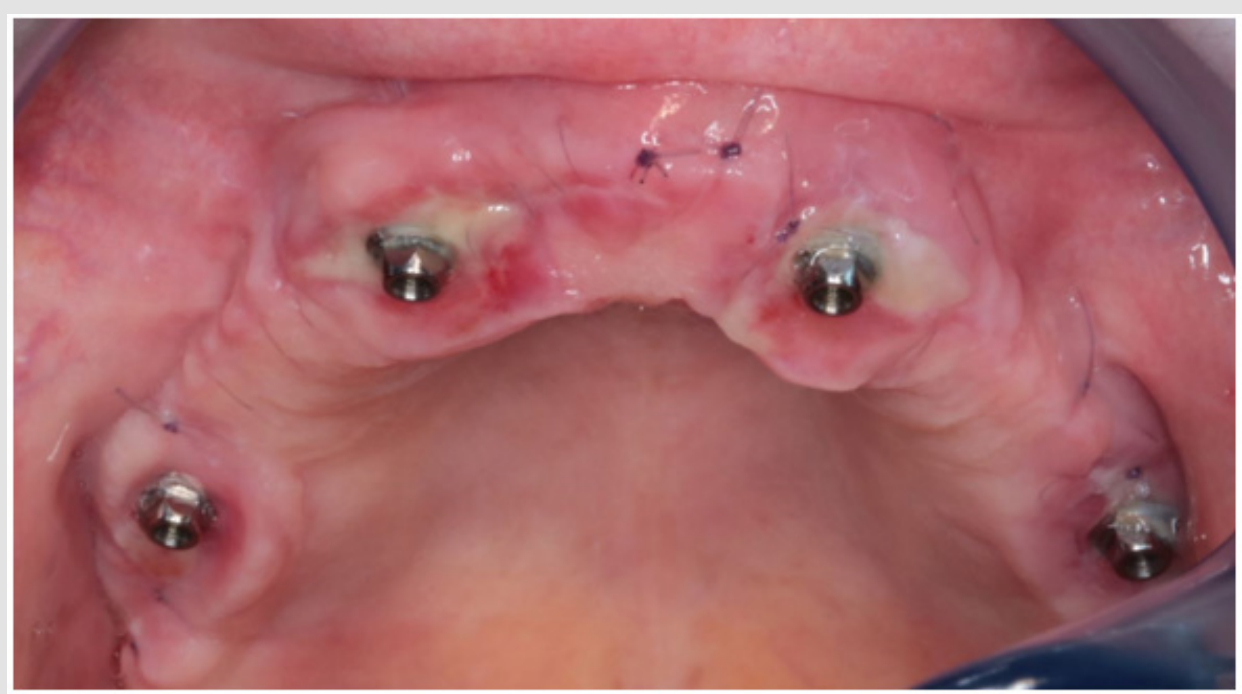

Figure 12: Condition at suture removal.

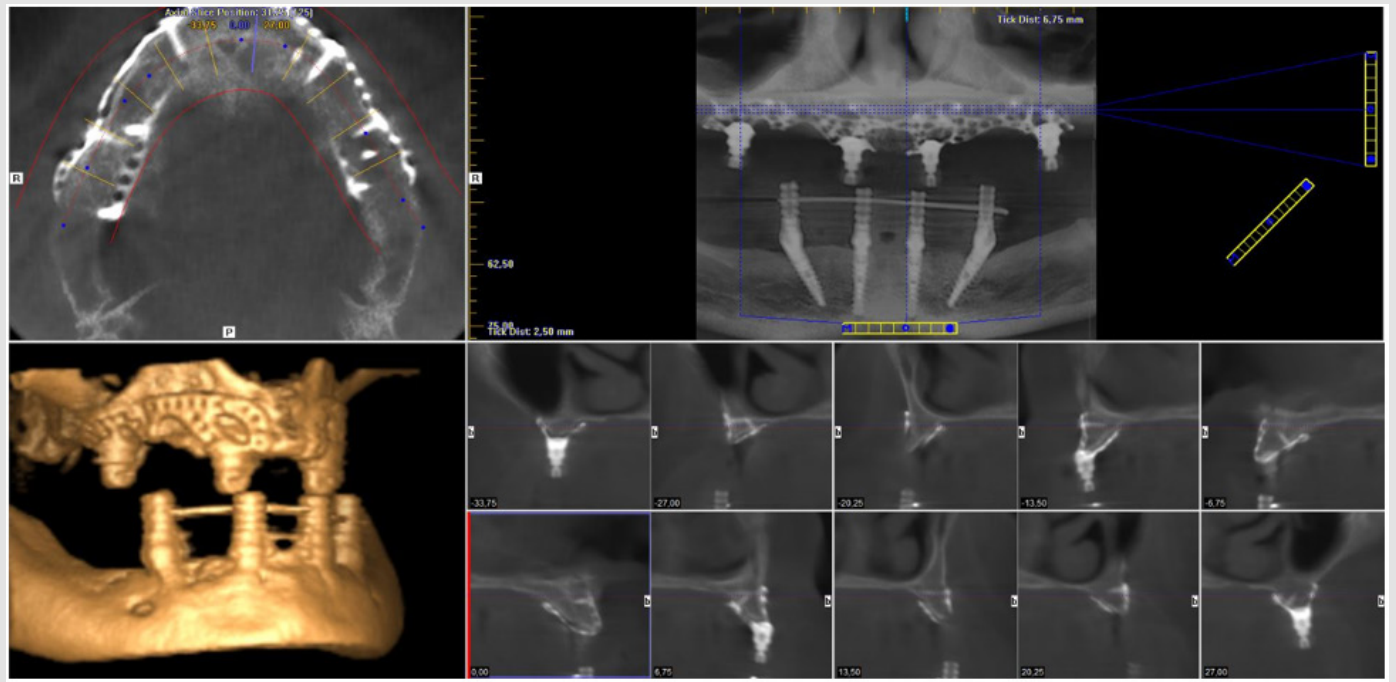

Figure 13: Control CBCT images. 


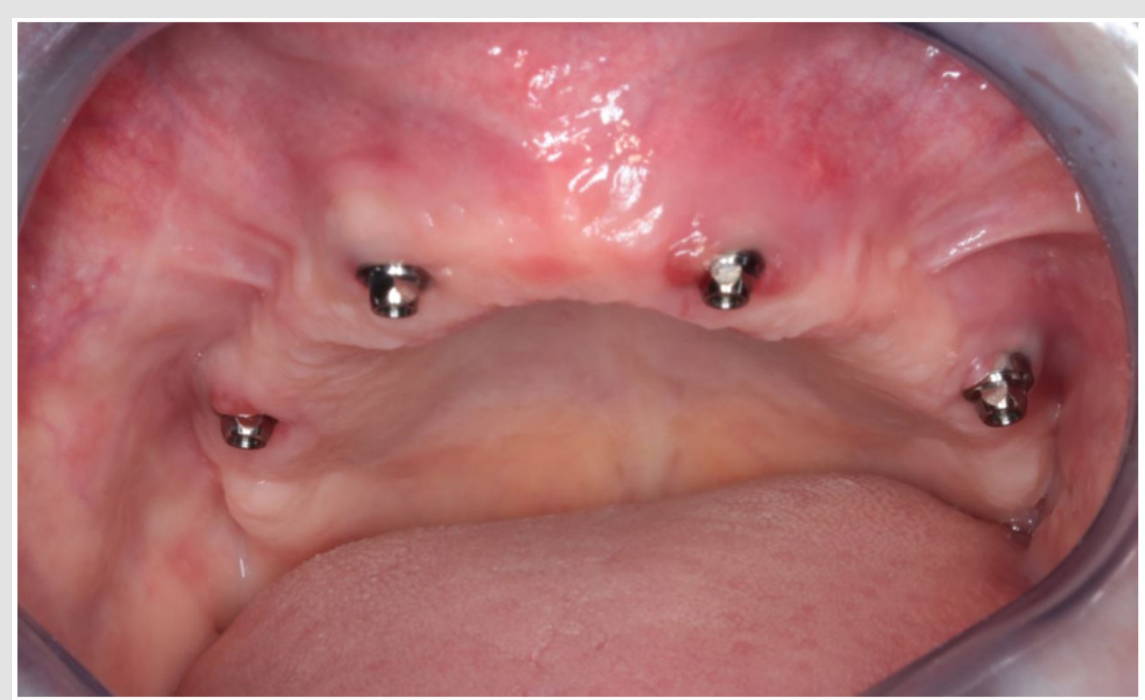

Figure 14: Healed state.

\section{Conclusion}

Good quality CBCT images that show all details of cortical bone volumes are indispensable for implant design. According to our experiences, at least half a year must be passed after possible dental extractions or any other dental surgeries e.g. corrective jaw surgery in order to achieve adequate healing of bone surfaces. Afterwards, CBCT images of proper quality can be made mapping the bone surfaces of the patient. Later surgical insertion procedure of the plate can be simplified if fixing screw position and length are both defined in advance. Creation of such custom-made implant reconstructions requires extensive professional experience from both the oral surgeon and the dental technician.

\section{Acknowledgement}

We would like to express our special thanks to Dr Csaba Csák, chief oral surgeon at Dent-Art-Klinik, and his surgical staff, who successfully conducted this case report and provided surgical images. "EFOP-3.6.1-16-2016-00017 Internationalization, initiatives to establish a new source of researchers and graduates, and development of knowledge and technological transfer as instruments of intelligent specializations at Szechenyi University".

\section{References}

1. DAHL G (1943) Om mojligheten for inplantation ikaken av metallskelett som bas eller retention for fasta eller avtagbara protester. Tidskrift 51: 440-449.

2. Fu Yuan Teng, Chia Ling Ko, Hsien Nan Kuo, Jin Jia Hu, Jia Horng Lin, et al. (2012) A Comparison of Epithelial Cells, Fibroblasts, and Osteoblasts in Dental Implant Titanium Topographies. Bioinorganic Chemistry and Applications 2012.

3. Yo Shibata, Yasuhiro Tanimoto (2015) A review of improved fixation methods for dental implants. Part I: Surface optimization for rapid osseointegration. Journal of Prosthodontic Research 59(1): 20-33.

4. Cerea M, Dolcini Ga (2018) Custom-Made Direct Metal Laser Sintering Titanium Subperiosteal Implants: A Retrospective Clinical Study on 70 Patients. Hindawi BioMed Research International 1-11.

5. Klaudia Kulcsár, János Kónya (2018) Moderization of cortically supported individual implants. Múszaki Tudományos Közlemények 8: 51-60.

6. Klaudia Kulcsár, János Kónya (2019) Numerical Analysis of Additively Manufactured, Individual Titanium Implants Designed in a Virtual Environment. Müszaki Tudományos Közlemények 10(1): 41-48.

7. Shahlaie M, Gantes B, Schulz E, Riggs M, Crigger M (2003) Bone density assessments of dental implant sites: 1 . Quantitative computed tomography. Int J Oral Maxillofac Implants 18(2): 224-231.

8. Aranyarachkul P, Caruso J, Gantes B, Schulz E, Riggs M, et al. (2005) Bone density assessments of dental implant sites: 2. Quantitative cone-beam computerized tomography. Int J Oral Maxillofac Implants 20(3): 416424 .

9. Gonda T, Kamei K, Maeda Y (2017) Determining Favorable Maxillary Implant Locations Using Three-Dimensional Simulation Soft-ware and Computed Tomography Data. Int J Prosthodont 30(1): 58-61.

10. Klaudia Kulcsár, János Kónya (2019) Geometric design of sleeve and abutment for subperiosteal implants using finite element analysis. Bánki Közlemények 2(1): 29-34.

11. János Kónya, Klaudia Kulcsár (2019) Examination of Laser Microwelded Joints of Additively Manufactured Individual Implants; Acta Materialia Transylvanica 2(1): 32-42. 
ISSN: 2574-1241

DOI: 10.26717/BJSTR.2020.25.004240

János Kónya. Biomed J Sci \& Tech Res

(C) This work is licensed under Creative

Submission Link: https://biomedres.us/submit-manuscript.php

$\begin{array}{ll}\text { BIOMEDICAL } & \text { Assets of Publishing with us } \\ \text { RESEARCHES } & \text { - Global archiving of articles } \\ & \text { - Immediate, unrestricted online access } \\ & \text { - Rigorous Peer Review Process } \\ \end{array}$

